\title{
On experiments on oil-spill booms in three Atlantic coastal zones: La Rochelle, Lorient and Brest
}

\author{
F. Muttin \\ Engineering School EIGSI La Rochelle, France
}

\begin{abstract}
The intrinsic performance of the protection of coastal zones of the Atlantic against oil-spills by using floating booms needs to be improved in the current conditions. To define a contingency plan in advance, a one-dimensional numerical code has been used for many years. A three-dimensional membrane finite-element method is proposed to give more complete results on boom geometry and boom stress. To improve the booms' performances and validate numerical methods three experiments are described. The first experiment is conducted in the open-sea harbour of La Rochelle, with current conditions higher than 3 knots. In the Lorient oil wharf an experiment attempt shows the constraints due to the uncertainties of a coastal zone with harbour infrastructure under extension and intensive maritime traffic. In the Elorn estuary, Brittany, France, a third experiment is described with current conditions bounded by 0.9 knots. The environmental performance of a floating boom is also evaluated using an economic approach. The budgets of these three experiments are evaluated and analyzed. These budgets estimate the technical and human efforts needed to use a boom in such coastal zones. The knowledge of both environmental and economical performances must be added to the theoretical performances given by numerical computations.
\end{abstract}

Keywords: spilled oil, floating boom, environmental evaluation, economic evaluation, numerical methods, scale-one experiments.

\section{Introduction}

The protection of the maritime environment against oil pollution is governed by several international conventions (MARPOL, Boon Agreement, ERIKA 
packages...) and by many international establishments (REMPEC, EMSA, OSRL...), as well as the initiative action of the World Bank [1] in terms of material and response.

Around the world many naval exercises, or drifts, are achieved every year to improve oil spill responses. These experiments target both operational and technical goals. During 2009, we can take as examples the drift involving China, Russia, Japan and Korea (NOWPAP, December 2009), and the EPC 09 exercise in the Mediterranean Sea between Bulgaria, Georgia, Greece, Latvia and the United States. During spring 2009, an exercise named Euronyme 2009 gathered French and Spanish vessels, and EMSA, in the Mediterranean Sea.

Maritime environmental protection against oil discharges is the objective of contingency pre-planning, such as the POLMAR plans in France, or oil industry response plans. These plans frequently use floating barriers, named booms. These structures are flexible devices, connecting mooring points, which are anchoraged along the sea bed, near a shore, or in a harbour. A boom can also be towed by a ship, in an estuary, or in high sea conditions. This eco-technology is used to contain, or deviate, floating oil pollution, before recovery by a skimmer.

The project BAR3D [2] aims to validate a three-dimensional (3D) numerical model used to improve the installation plan of floating oil barriers (Muttin et al. [3] and Muttin [4]). The numerical computations verification uses necessary experiments. For that purpose several experiments at scale-one have been performed in three locations on the French Atlantic coast. The measurements on the boom geometry and on the boom stress can be compared with the numerical results.

The numerical code is developed to predict the geometry and the stress inside the boom device and its mooring system. The $3 \mathrm{D}$ computation is initialized by a one-dimensional (1D) computation done with the software FORBAR. This initialisation step permits one to reduce the computation time by starting the solution from an approximation on a coarse grid (Adams [5] and Nobile [6]).

The main objective of this paper is the description of the three scale-one experiments of oil barriers, in coastal, estuary and harbour waters. Experiments permit the improvement of boom installation as well as an evaluation of the technical and human efforts involved. These means are presented in various coastal environments of the Atlantic.

The paper is organized as follows. The La Rochelle, Lorient and Brest experiments are described in sections 2, 3 and 4, from the environmental, numerical and economical points of view. Section 5 presents the discussion of the economical and environmental dimensions.

\section{La Rochelle harbour sea opening}

This experiment is conducted in the deep sea harbour of La Rochelle. The experimental zone is located inside the Anse Saint-Marc, in the vicinity of the viaduct of the La Rochelle oil terminal. Between 5 and 13 May 2008, a floating boom was installed in the sea opening between Ré Island, the oil terminal and the harbour infrastructure, which is under extension on the sea. The boom device 
is $100 \mathrm{~m}$ long. It is anchoraged within five mooring points. The boom device is composed of rigid floats. The South end-point of the boom plan is anchoraged on a buoyancy coffer connecting a mooring chain on a dead mass. The North endpoint is attached to a buoy connecting a mooring chain on another dead mass. Three intermediary points are anchoraged on both sides of the boom using Brittany anchors weighting $35 \mathrm{~kg}$. A total of six anchors are moored. Each mooring line is perpendicular to the side of the boom, e.g. the South-North endpoints of the boom plan. The installation period corresponds to a high tide coefficient.

Figure 1 shows the boom plan in the South of the oil terminal viaduct. Two artificial viaduct pile foundations are near the boom plan North end-point.

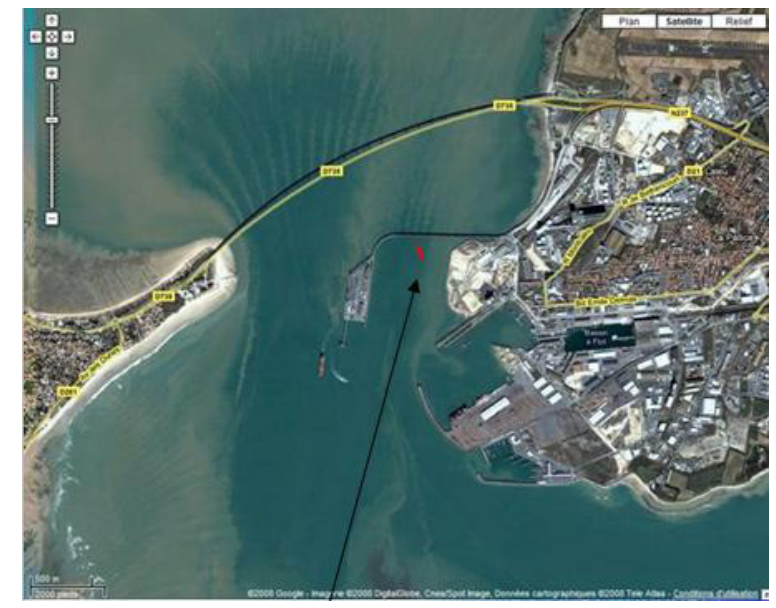

Figure 1: Location of the boom plan $100 \mathrm{~m}$ long of the La Rochelle harbour experiment.

The cardinal sides of the experimental zone are respectively, a sea opening (South), an artificial dock (West), a sea opening with viaduct piles (North) and a cliff (East) with the new harbour infrastructure. The sea bottom morphology is an estuarine mudflat, surrounding a rocky flat.

The experiment is conducted by the partners of the BAR3D national project, with the main contributions of the National Harbour of La Rochelle and the "Phares et Balises" Subdivision. The boom is delivered by the company TOTAL SA.

The following figure shows the boom plan. At that moment the sea current reverses after its zero value of a tide-down period end. The low tide is back to this moment. Figure 2 is a view from North to South, taken from the oil terminal viaduct.

The main result observed in figure 2 is the four adjacent curves take by the boom device. A geometrically singular point corresponds to the tension of a mooring line. Note that these three singular points are not aligned with the endpoints of the plan. It is a consequence of the installation of the six intermediary 


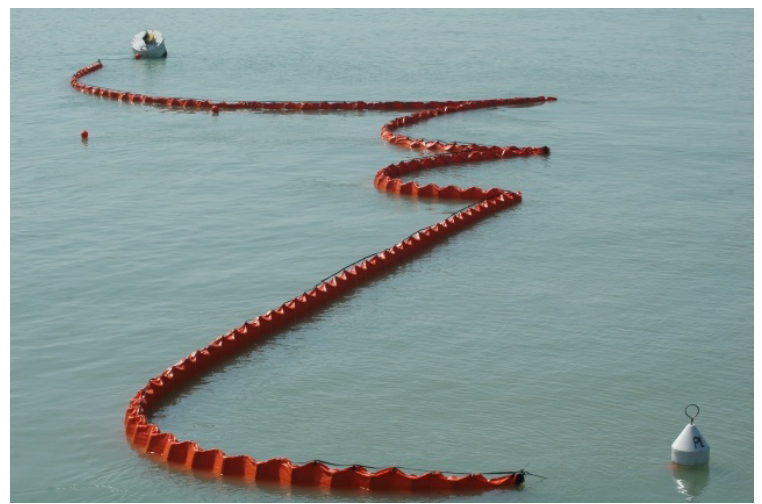

Figure 2: The boom plan under a small sea current at the beginning of a tide-up period.

Table 1: Budget repartitions between the partners for the La Rochelle scale-one experiment.

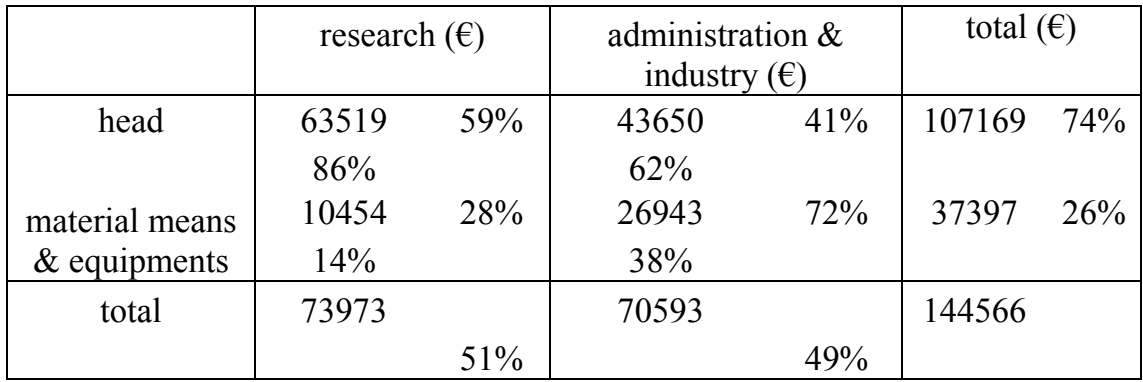

mooring lines during an opposite current orientation corresponding to a tide-down period. During that installation period the entire boom device is stressed by the current and is attached solely by its end-points, e.g. boundaries. The smooth shape of the boom at that moment can be recognized in figure 2 by looking at the end-points and the three singular points.

Another mechanical limitation of this boom plan is the absence of additive buoyancies at the three singular points. Here, the buoyancy comes solely from the boom rigid floats. The tension of a mooring line increases when the sea current increases. Consequently, the boom buoyancy can become insufficient to balance the vertical component of the mooring line tension. It is observed during this experiment the sinking of the boom locally, when the sea current is high. This effect can be reduced by using inflated tubes instead of rigid floats.

Here follows the economic evaluation of this experiment. The repartitions of the budget between the participants are set by a contingency table (Greenacre [7]). The horizontal direction of the table gives the natures of the budget, while the vertical repartition concerns the partnership kinds. 
In table 1 we note the high proportion of the equipments provided by the administration and the industry, showing the numerous material means involved. It concerns the boom device, its mooring system, the three pneumatic boats, the mooring boat service, the towing vedette and the instrumentations. The principal budget comes from the head resources involved by the research partners. This includes the preparation of the test and the measurements during the experiment. The preparation contains the numerical computations of the boom plan by using a 1D model. The measures done are for example the sea current velocity by an ADCP sensor and the boom device tension by a dynamometer on the coffer at the South end-point.

\section{Lorient petroleum wharf}

This experiment is a test attempt. The experiment has been delayed because of the presence of much public transportation shipping in the experiment zone, the extension of the concerned oil terminal quay and several uncertainties on the marine current and the water bathymetry.

The test has been expected for the second semester of 2008. The boom device floats are composed of inflated tubes. The boom device is a single section of 100 $\mathrm{m}$, or $70 \mathrm{~m}$ long, for either former or new quay infrastructure. On one end the boom section moves vertically on a stressed cable. It permits the boom plan respecting the sea level variation during tide. It is located near the tanker quay. On its other end the boom is anchoraged on a buoyancy coffer moored with a chain on a dead mass. It is located near the shore line.

The cardinal sides of the experimental zone are respectively, the Lorient harbour channel (South), a fishing harbour quay and a public transportation quay (West), a rocky coastal structure (North) and a two-rivers estuary (East). The sea bottom is an estuarine tidal mudflat. It exists along the quay an artificial bed allowing tanker vertical displacement with tide. The figure 3 is a view from East to West of the zone, showing the boom plan on the former oil wharf.

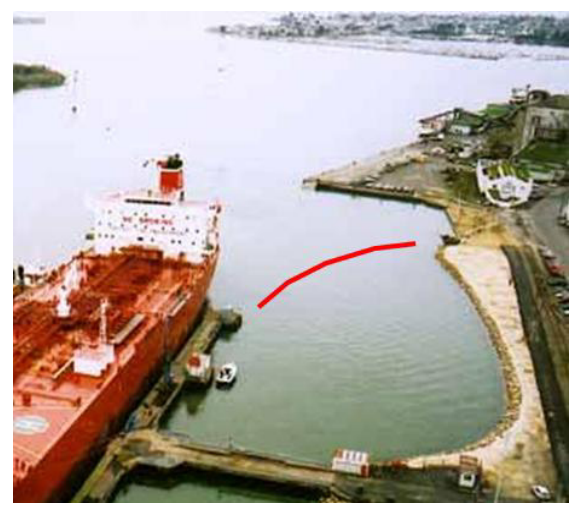

Figure 3: The boom plan of the experiment attempt on the former oil wharf of Lorient harbour (view from East to West). 
Table 2: Budget repartitions between the partners for the Lorient experiment.

\begin{tabular}{|c|c|c|c|c|c|c|}
\hline & \multicolumn{2}{|c|}{ research $(€)$} & \multicolumn{2}{|c|}{$\begin{array}{l}\text { administration \& } \\
\text { industry }(€)\end{array}$} & \multicolumn{2}{|c|}{ total $(€)$} \\
\hline head & 9347 & $44 \%$ & 12040 & $56 \%$ & 21387 & $90 \%$ \\
\hline & $96 \%$ & & $86 \%$ & & & \\
\hline \multirow{2}{*}{$\begin{array}{c}\text { material means } \\
\& \text { equipments }\end{array}$} & 400 & $17 \%$ & 1900 & $83 \%$ & 2300 & $10 \%$ \\
\hline & $4 \%$ & & $14 \%$ & & & \\
\hline \multirow[t]{2}{*}{ total } & 9747 & & 13940 & & 23687 & \\
\hline & & $41 \%$ & & $59 \%$ & & \\
\hline
\end{tabular}

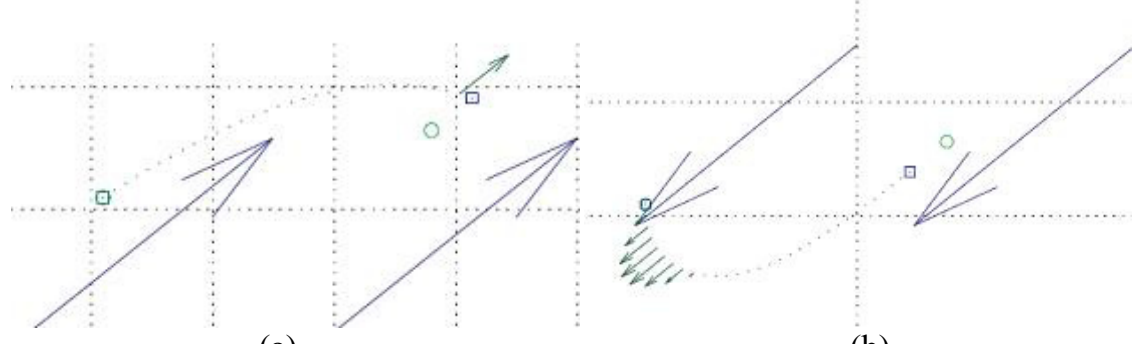

(a)

(b)

Figure 4: Lorient oil wharf boom plan computations: (a) midterm tide-down period; and (b) midterm tide-up period.

The preparation of this experiment is conducted by the partners of the BAR3D project, the Oil Storage Facilities of TOTAL SA in the Lorient Harbour and the local authorities, CCI Lorient and the Regional Council of Brittany. Let us give the economic evaluation of the experiment. The repartitions of the budget between the partners are given in the contingency table 2 .

The budget repartition underlines the principal contribution of the administration and the industrial partner. Despite the fact that the experiment is an attempt, the contribution of research work is significant. During this attempt, we do not involve any water pollution response material and responders.

Figures 4(a) and (b) show the results of the computations of the boom plan at both midterm tide-up and midterm tide-down periods. The computation solves the tension cable equilibrium equation being a first order non-linear differential equation. A finite-difference scheme is used with a fixed-point method. The iterations proceed on the tension on one end of the boom until the other end converges to the desired anchorage location. The sea current is taken parallel to the tanker quay.

The main observations in the figures 4.a and 4.b are on their right sides. We can see the large displacement of the boom plan end, attached on a coffer, given by a small square on the figures. The coffer is moored by a chain on a deadmass, represented by a small circle. This large amplitude is a consequence of a 
practical constraint on the mooring chain length. This one must be strictly higher than the sea level change of the tide periods considered. This displacement can be reduced solely by a reduction of the mooring chain length. Note that a reduced mooring chain length renders it more vertical during high tide periods. In practice, the mooring chain length is taken as three times the maximal water height. The constraint comes from the vertical component of the traction of the mooring chain which can favour the drag of the dead mass.

\section{Brest Elorn estuary}

The experimental zone is located near the right bank of the Elorn estuary, at the level of the small city of Relecq-Kerhuon, located at the East of the Brest bay, Iroise sea, at the North-East of the Iroise Bridge. Between 2 and 9 November 2009, a $210 \mathrm{~m}$ long boom is installed between four anchorages points, $60 \mathrm{~m}$ equidistant. The boom device floats are inflatable tubes. The installation period corresponds to the beginning of the winter season.

The cardinal sides of the experimental zone are respectively: the Elorn estuary (South), a mooring zone for yachting (West), a rocky coastal structure (North) and the Elorn River and its natural channel (East). The sea bottom of the experimental zone is an estuarine tidal mudflat. The natural channel is near the boom plan East end.

The test period corresponds to a high tide coefficient. The Elorn river debt is heavy during that period, as a consequence of rains. The Elorn flows to SW. The sea current is NE, when tide goes up. The maximal sea level change is [1.29, 7.04] $\mathrm{m}$ corresponding to around a $6 \mathrm{~m}$ tide height. Figure 5 shows the Elorn estuary and the boom plan.

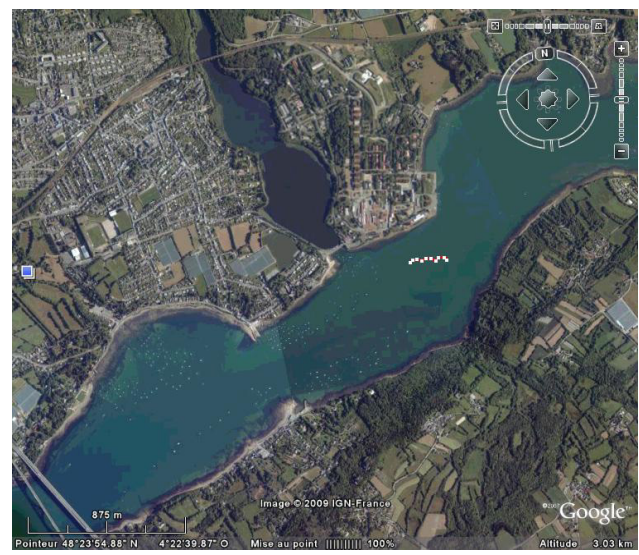

Figure 5: The boom plan (the boom is $210 \mathrm{~m}$ long) for the Elorn estuary experiment. 


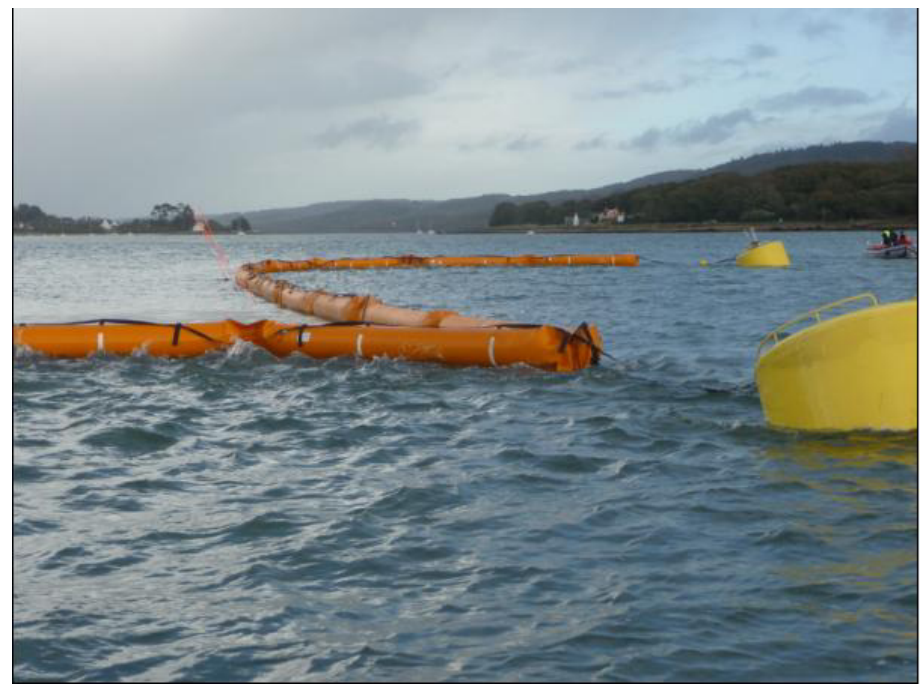

Figure 6: The third section of the boom plan for the Elorn estuary during a tide going-up period (view from west to east).

The experiment is conducted by the partners of the BAR3D project, with the valuable contributions of the "Stock POLMAR" of Brest, the "Phares et Balises Subdivision du Finistère". The boom is delivered by the "Stock POLMAR".

Figure 6 shows the third section of the Elorn boom plan, during a tide goingup period. This third section is the East side of the boom plan. Three measurement light bars are installed at the quartile lengths of this boom section. Each bar is attached vertically on the bottom part of the sub-sea skirt of the boom device. It indicates locally the vertical angle of the boom skirt bottom. It is admitted that skirt angle amplitude higher than $10^{\circ}$ is inefficient to contain floating oil (Violeau et al. [8]).

A result observed during the experiment is the large amplitude of the boom skirt angle, which is higher than $20^{\circ}$. We note that the angle measured is on the tangent at the skirt bottom and the vertical. As a consequence it cannot be concluded that the boom is inefficient. For boom efficiency, the angle of the skirt to be taken into account is the cord between the skirt top-bottom and the vertical. Our measure can be improved by using the bars attached on the full height of the skirt.

The next figure shows the stress map in the third boom device. It is computed by using a 3D membrane finite-element method (Muttin [9]). The mesh uses 21 sections of nodes given by the initialization stage. Each nodal position of the boom mesh at the sea surface is initialized by using a $1 \mathrm{D}$ numerical model. The current velocity is $0.4 \mathrm{~m} / \mathrm{s}$. The angle between the boom device end-points and the current is $38.70^{\circ}$. On the two coffers visible in figure 6 , the computed tensions of the boom device are $193 \mathrm{~kg}$ for the first coffer, and $201 \mathrm{~kg}$ for the far East coffer. 


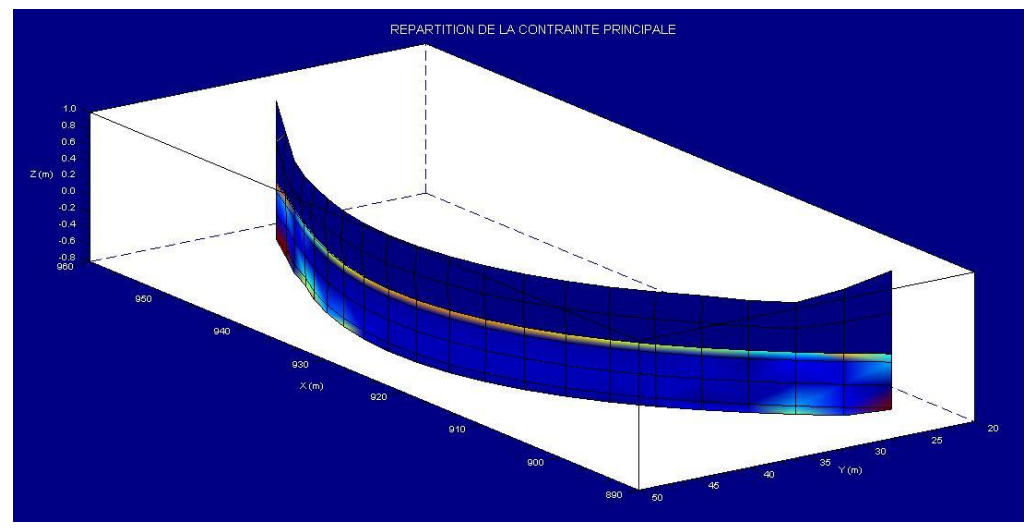

Figure 7: The stress map in the third section of the boom plan for the Elorn estuary (view direction similar in figure 6).

Table 3: Budget repartitions between the partners for the Elorn estuary experiment.

\begin{tabular}{|c|c|c|c|c|c|c|}
\hline & \multicolumn{2}{|c|}{ research $(€)$} & \multicolumn{2}{|c|}{$\begin{array}{c}\text { administration \& } \\
\text { industry }(€)\end{array}$} & \multicolumn{2}{|c|}{ total $(€)$} \\
\hline \multirow[t]{2}{*}{ head } & 45302 & $53 \%$ & 39800 & $47 \%$ & 85102 & $61 \%$ \\
\hline & $71 \%$ & & $53 \%$ & & & \\
\hline \multirow{2}{*}{$\begin{array}{c}\text { material means } \\
\& \text { equipments }\end{array}$} & 18763 & $34 \%$ & 35711 & $66 \%$ & 54474 & $39 \%$ \\
\hline & $29 \%$ & & $47 \%$ & & & \\
\hline \multirow[t]{2}{*}{ total } & 64065 & & 75511 & & 139576 & \\
\hline & & $46 \%$ & & $54 \%$ & & \\
\hline
\end{tabular}

The map in figure 7 indicates a concentration of the stress in the leach located at the upper part of the skirt under the boom float.

Let us now look at the economic evaluation of this experiment. The budget repartitions between the partners are showed using a contingency table.

The budget repartition of the Elorn estuary experiment is similar with the La Rochelle experiment. The head for the research activity is the principal component. The material means and equipments are mainly involved by the administration and the industry. That suggests an invariant budget structure for such experiment. The total amount level shows the effort to install floating boom for coastal protection against oil pollution.

\section{Discussion}

\subsection{Economic analysis}

An economic analysis is given on the following table. It shows some economic indicators, as the human effort needed, given in man*months and the ratio 
Table 4: $\quad$ Some economic indicators versus the three oil boom experiments in Atlantic coastal zones.

\begin{tabular}{|c|c|c|c|}
\hline & La Rochelle & Lorient & Brest Elorn \\
\hline $\begin{array}{c}\text { human effort } \\
\text { (man*month) }\end{array}$ & 12 & 3 & 9 \\
\hline $\begin{array}{c}\text { public/private } \\
\text { budgets (\%) }\end{array}$ & $29 \% / 71 \%$ & $18 \% / 82 \%$ & $47 \% / 53 \%$ \\
\hline $\begin{array}{c}\text { cumulative } \\
\text { ratio of } \\
\text { research funds }\end{array}$ & 4,3 & 5,0 & 4,9 \\
\hline
\end{tabular}

between the public budgets and the private ones. The cumulative effect of the state funds is given. It concerns the BAR3D project part dedicated to experiments.

We underline a quasi constant cumulative effect of the research funds. It appears as quasi invariant in the three experiments. This factor is closed to 5 . It proves the high interest of the involved partners for such experiments. It suggests that the environmental technology properties verification and testing must contain that kind of economic indicators.

Concerning the two performed experiments (La Rochelle, Brest Elorn) the ratio between the public and private budgets appears lower or higher than the targeted 1/3-2/3 repartition suggested by national research policies. It is expected that such research activities on environmental performance verification and improvement are compatible with a sustainable development goal from an economic point of view (Seager et al. [10]).

\subsection{Environmental analysis}

The principal environmental uncertainty during the experiment of La Rochelle comes from the amplitude of the sea current. The current can be higher than the existing measures. It is expected to be a consequence of the recent embanking of the sea water zone for the harbour infrastructure extension. The strait between the Ré Island and the coast is reduced and the current will increased according to a Venturi effect. It suggests before any boom experiment to record the sea current in the zone concerned.

Another environmental uncertainty results from the Elorn experiment. In an estuary two flows are superposed. The river flows down, while the tides make the sea water flow up or down. In the Elorn estuary experimental zone, the current of the water surface does not take opposite directions when the tide goes up or down. It may be a consequence of the water stratification and the estuary geomorphology, with a bending geometry of the channel in the vicinity of the zone.

The experiment attempt at the oil wharf of Lorient can be interpreted as the difficulty to perform a test at scale-one in a harbour where the geomorphology contains uncertainties, and where the port infrastructures are under 
transformation. It can be note the difficulty to install during several days a boom plan and a measurement unit in a harbour zone where the maritime circulation can be intensive (Gottinger [11]).

\section{Conclusion}

The performances evaluation and improvement of oil booms are a risky task from two points of view.

\subsection{Technical performances}

A main conclusion from the La Rochelle and Elorn estuary experiments is the lack of knowledge in the sea current conditions. Our main recommendation is an in-situ recording of the environmental conditions before the experiment will be made, even if existing measures are available. A lack of quality in the variables used in the computations will result in imprecise numerical results, even being $1 \mathrm{D}$ and $3 \mathrm{D}$, for decision making. The pre-planning of response plan can be improved in that direction (Harrald [12]).

\subsection{Economical performances}

The conclusion is a valuable invariance of the budget structure for the performed experiments of La Rochelle harbour and Elorn estuary. It suggests that when an experiment is envisaged this budget structure can be adopted. The economic performance evaluation appears as a monitoring process of a boom plan. Nevertheless, the attempt of the Lorient experiment shows that a significant budget can be spent without the certainty that the experiment can be performed. It suggests that even if the budget structure of an experiment is quite invariant the performing of an experiment is uncertain.

\section{Acknowledgements}

This research is supported by the French Research Agency ANR, and ADEME, under grant $\mathrm{n}^{\circ}$ BAR3D/0694C0067, project $\mathrm{n}^{\circ}$ ANR-06-ECOT-003-01. The author acknowledges the French framework, PRECODD, on Environmental Technologies and Sustainable Development. The network "Recherche et Innovation Technologique RITMER", "Pollutions Marines Accidentelles et leurs Conséquences Ecologiques" and "Pôle Mer Bretagne" are gratefully acknowledged.

\section{References}

[1] World Bank, Implementation Completion Report, Report $\mathrm{n}^{\circ} 34859$, December 29, 2005.

[2] BAR3D project, http://bar3d.eigsi.fr 
[3] Muttin, F., Nouchi, S., Numerical Study of Oil Spill Containment Boom by the Finite-Element Method, Proc. of Eighth International Conference on Modelling, Monitoring and Management of Water Pollution, Water Pollution VIII Conference, Bologna, Wessex Institute of Technology, pp. 245-254, 2006.

[4] Muttin, F., Oil spill boom modelling by the finite-element method, Proc. of Ninth International Conference on Water Pollution: Modelling, Monitoring and Management, Water Pollution IX, WIT Transactions on Ecology and the Environment, Wessex Institute of Technology and Alicante University, Vol 111, pp. 383-392, 2008.

[5] Adams, M. F., Parallel multigrid solvers for 3D unstructured finite element problems in large deformation elasticity and plasticity, International Journal for Numerical Methods in Engineering, 48(8), pp. 1241-1262, 2000.

[6] Nobile, F., Coupling strategies for the numerical simulation of blood flow in deformable arteries by 3D and 1D models, J. Math. Comput. Modelling, 49(11-12), pp. 2152-2160, 2009.

[7] Greenacre, M. , Correspondence Analysis in Practice, Interdisciplinary Statistics, Chapman \& Hall, Taylor \& Francis Group, $2^{\text {nd }}$ edition, 2007.

[8] Violeau, D., Buvat, C., Abed-Meraim, K., De Nanteuil, E., Numerical modelling of boom and oil spill with SPH, Coastal Engineering, 54, pp. 895-913, 2007.

[9] Muttin, F., Structural analysis of oil-spill containment booms in coastal and estuary waters, Applied Ocean Research, 30(2), pp. 107-112, 2008.

[10] Seager, T.P., Tuler, S.P., Kay, R., Linkov, I., Satterstrom, F.K., Environmental Performance Metrics For Oil Spill Response, Technical Report, Coastal Response Research Center, University of New-Hampshire and NOAA, January 31, 2006.

[11] Gottinger, H.W., Monitoring pollution accidents, Eur. J. Oper. Res., 104, pp. 18-30, 1998.

[12] Harrald, J.R., Contingency planning: building the infrastructure for crisis decision making, International Journal of Mass Emergencies and Disasters, 8(2), pp. 137-150, 1990. 